\title{
Raag detection in music using supervised machine learning approach
}

\author{
Ekta Patel* and Savita Chauhan \\ Technocrats Institute of Technology (Excellence), Bhopal, MP, India
}

\section{(C2017 ACCENTS}

\begin{abstract}
There are several research work is in progress in the direction of Raag detection. Raag is one of the melodic modes used in traditional South Asian music genres such as Indian classical music and qawwali. It can be said that Indian classical music is always set in a räga. Non-classical music such as popular Indian film songs and ghazals sometimes use raagas in their compositions. There are several obstacles in accurate Raag detection technique. The major challenges are the complex parameters like pitch and mood in the music, skipping extra tones, conversion of different data attributes and Raag tempo. In this paper different classifiers like Bayesian net, naive Bayes, support vector machine (SVM), J48, decision table, random forest, multi-layer perceptron and PART performance are analyzed. The music features are extracted using MIRToolbox in MATLAB. These extracted features are arranged in arff file format. WEKA tool is used. The results shown below clearly indicate that the accuracies of all the classifiers after the discretization have increases considerably. While the accuracy of the probability based classifier are best in this Raag detection from music.
\end{abstract}

\section{Keywords}

Raag, Thaats, Nä̈ve bayes, Decision tree, Support vector machine (SVM).

\section{Introduction}

In the ancient times music is the heart of India and the other countries. The root of Indian classical music is very rich. It includes many gharana and the different style and tradition for those gharana. Bhatkhande [1] describes the culture of these gharana and their music forming methods. Indian classical music can be categorized into two main streams like North Indian and South Indian based music and styles. Raag is essential building blocks in Indian classical music. Melodic mode of music comprises of five to nine musical notes is also termed as Raag.

In the recent past there are several works have been done on musical analysis and specially the Indian classical music, generating lot of new insight into this domain. The research related to musical information retrieval is thus attracting the interest of so many researchers. The music is categorized in different thaats based on which the ragas are derived. Different Distributions of notes making different note structures are called thaats.

The Latest research methods and techniques are focusing on carnetic raga and its analysis.

\footnotetext{
*Author for correspondence
}

The music research and its analysis play an important role in finding the raga patterns on various ways. To identify their variety the thaat categorization is available in [1]. It is a system that is very relevant with this type of categorization. In 2013, Sharma et al. [2] proposed that thaats are classified in 10 different ways which are as follows: Bilawal, kalian, Todi, Bhairavi, Marwa, Kafi, Bhairav, Khamaj, Purvi, Asavari. These Thaats (raags) possess very different structural patterns so they can be distinguishingly identifiable [1].

\section{Related work}

In 2013 Chordia et al. [3] found that how the raga and the tonic are both mutually attached to each other. In their study they introduced some technique to identify the raga by the histogram approach and the Hidden markov model technique. The various studies in the same field discussed. There results suggest that the tonal features based on pitch distributions are robust, reliable features that can be applied to complex melodic music. In 2002, Tzanetakis [4] has also proposed various schemes in the English music classification based on their moods and styles of the performer as well as songs genre classification. Clustering is suggested as the classifier [5]. Sentiment analysis of movie review based on naïve Bayes and genetic algorithm is suggested in [6]. Since this methodology depends on the 
likelihood it can be connected to a wide assortment of spaces and results can be utilized as a part of numerous ways [6]. It doesn't require expansive measure of information before preparing to start. These calculations are computationally quick to settle on choices [7]. SVM classifier which finds a hyper plane that clearly separates the sample points of different labels [8]. It divides such that sample points of both labels and class are on different sides of hyper plane. Decision tree and image processing techniques are suggested as the efficient classifier in $[9,10]$. Mi Classifier: It is denoted as multi-instance classifiers. It comprises of numerous occasions in an illustration, yet perception of one class is conceivable just for every one of the examples [11]. Super-set and sub-set approach is suggested in [12]. Log file based classifier was suggested in [13]. Bayes net is a widely used technique which takes at the essential Bayes hypothesis and structures a Bayesian system in the wake of computing restrictive likelihood on every hub. It is a graphical model which is probabilistic in nature and depicts a gathering of discretionary variables alongside their restrictive conditions through a coordinated non-cyclic chart [14]. Logistic system utilizes relapse to anticipate the likelihood of a result which can have just two qualities. One or a few indicators are utilized to make the expectation [15]. Image based keying (IBK) remains for occurrence based information representation of the preparation cases and does not close or foresee a standard set or a choice tree [16]. JRip system executes a proposed guideline learner and aggregate blunder pruning strategy to diminish mistake. It depends on affiliation rules with diminished blunder pruning methods, in this way making it a powerful strategy [17]. PART utilizes a separation and vanquishes way to deal with build a $\mathrm{C} 4.5$ decision tree in part for every cycle indicating the ideal guideline affiliation. Utilizing an entropic separation measure strategy, it performs occurrence based learning. J48 is an upgraded variant of $\mathrm{C} 4.5$ which spins on the ID3 calculation with some additional usefulness to determine issues that ID3 was clumsy [18]. Classification based on neural network is suggested in [19]. Mood based Bollywood music classification is suggested in [20]. In [22-24] a segmentation of phrases through identification of nyas and computes similarity with the reference characteristic phrase has been proposed. Table 1 shows the limitations in the existing techniques.

Table 1 Comparison based on classifier techniques

\begin{tabular}{|c|c|c|c|c|c|}
\hline S.NO. & Authors & Classifier & Category & & Limitations \\
\hline 1. & Chakraborty et al. [25] & Naive Bayes & $\begin{array}{l}\text { Probability } \\
\text { classifier }\end{array}$ & based & $\begin{array}{l}\text { This is a probability based } \\
\text { classifier based on Naive Bayes } \\
\text { conditional probability. It fails on } \\
\text { no occurrences of classes. }\end{array}$ \\
\hline 2. & Chakraborty et al. [25] & Bayesian Net & $\begin{array}{l}\text { Probability } \\
\text { classifier }\end{array}$ & based & $\begin{array}{l}\text { This is a probability based } \\
\text { classifier based on Naive Bayes } \\
\text { conditional probability. It only } \\
\text { predicts based on the posterior } \\
\text { information. }\end{array}$ \\
\hline 3. & Roy et al. [26] & $\mathrm{J} 48$ & $\begin{array}{l}\text { Tree } \\
\text { approach }\end{array}$ & based & $\begin{array}{l}\text { It is enhanced version of C } 4.5 \\
\text { algorithm and used ID3. Its } \\
\text { reliability is only on the precise } \\
\text { internal and external data } \\
\text { feeding. }\end{array}$ \\
\hline 4. & Roy et al. [26] & Random Forest & $\begin{array}{l}\text { Tree } \\
\text { approach }\end{array}$ & based & $\begin{array}{l}\text { It is also a decision tree based } \\
\text { approach but have more accuracy } \\
\text { as compared to J } 48 \text {. }\end{array}$ \\
\hline 5. & Roy et al. [26] & Random Tree & $\begin{array}{l}\text { Tree } \\
\text { approach }\end{array}$ & based & $\begin{array}{l}\text { It generates a tree by randomly } \\
\text { selecting branches from a } \\
\text { possible set of trees. }\end{array}$ \\
\hline 6. & Gómez et al. [27] & REPTree & $\begin{array}{l}\text { Tree } \\
\text { approach }\end{array}$ & based & $\begin{array}{l}\text { It uses gain and variance for } \\
\text { prediction. But fails in the case of } \\
\text { no variance. }\end{array}$ \\
\hline
\end{tabular}


Ekta Patel et al.

\begin{tabular}{|c|c|c|c|c|}
\hline S.NO. & Authors & Classifier & Category & Limitations \\
\hline 7. & Ross et al. [21] & Phrases & $\begin{array}{l}\text { Segmentation of } \\
\text { phrases }\end{array}$ & $\begin{array}{l}\text { This method was efficient in } \\
\text { segmentation of phrases through } \\
\text { identification of nyas and } \\
\text { computes similarity with the } \\
\text { reference characteristic phrase. } \\
\text { But fails in case of non-judging } \\
\text { the references. }\end{array}$ \\
\hline 8. & Priya et al. [28] & $\begin{array}{l}\text { C4.5 decision tree } \\
\text { algorithm, } \\
\text { Random Tree and } \\
\text { Rule Induction } \\
\text { algorithm }\end{array}$ & Hybrid approach & $\begin{array}{l}\text { C4.5 decision tree algorithm, } \\
\text { Random Tree and Rule Induction } \\
\text { algorithm were utilized to } \\
\text { classify the Melakartha raga and } \\
\text { the Janya raga. }\end{array}$ \\
\hline 9. & Kumari et al. [29] & $\begin{array}{lr}\text { KNN } & \text { classifier } \\
\text { and } & \text { SVM } \\
\text { classifier } & \end{array}$ & Hybrid approach & $\begin{array}{l}\text { For data classification they used } \\
\text { different types of classifier just } \\
\text { like KNN classifier and SVM } \\
\text { classifier they gives approximate } \\
87 \% \text { and } 92 \% \text { accuracy } \\
\text { respectively. }\end{array}$ \\
\hline 10. & Chordia et al. [30] & $\begin{array}{l}\text { Bayesian decision } \\
\text { rule }\end{array}$ & $\begin{array}{l}\text { Probability based } \\
\text { classifier }\end{array}$ & $\begin{array}{l}\text { Their system computes the pitch- } \\
\text { class distribution and uses a } \\
\text { Bayesian decision rule to classify } \\
\text { the resulting twelve dimensional } \\
\text { feature vectors, where each } \\
\text { feature represents the relative use } \\
\text { of each pitch class. It only } \\
\text { predicts based on the posterior } \\
\text { information. }\end{array}$ \\
\hline 11. & Rao et al. [31] & Machine learning & $\begin{array}{l}\text { Learning } \\
\text { training }\end{array}$ & $\begin{array}{l}\text { They used machine learning } \\
\text { methods on labeled databases of } \\
\text { Hindustani and Carnatic vocal } \\
\text { audio concerts to obtain phrase } \\
\text { classification on manually } \\
\text { segmented audio. Dynamic time } \\
\text { warping and HMM based } \\
\text { classification are applied on time } \\
\text { series of detected pitch values } \\
\text { used for the melodic } \\
\text { representation of a phrase. }\end{array}$ \\
\hline 12. & Sell et al. [32] & $\begin{array}{l}\text { logistic } \\
\text { regression, K-NN } \\
\text { and SVM }\end{array}$ & Hybrid approach & $\begin{array}{l}\text { They have applied machine } \\
\text { learning techniques (logistic } \\
\text { regression, K-NN, SVM). It } \\
\text { creates the best overall classifier. }\end{array}$ \\
\hline
\end{tabular}

\section{Problem statements}

After studying several research works the following gaps have been analyzed in the previous techniques.

1. Key phrases identification is important as it is capable in extracting the maximum instances.

2. The attributes considered should be compared with social behaviors also.

3. Pitch and mood identification can be used as the training subset.
4. Compositions with similar patterns and dissimilar patterns should be identified separately.

5. Segmentation of the signal should be detected at the same frequency.

\section{Proposed work}

In this work features of the music are extracted using MIRToolbox in MATLAB. These extracted features are arranged in arff file format. WEKA tool is used, which is a machine learning tool works on the arff 
file format. The Raag detection is performed on the musical file from which features are extracted. The following classifiers are used for Raag detection:

- Bayesian net

- Naive Bayes

- Support vector machine (SVM)

- J48

- Decision table

- Random forest

- Multi-layer perceptron

- PART

Accuracy of all the classifiers is calculated along with precision and recall. Then discretization is applied on dataset and then again all the classifiers are applied. The accuracy of classifiers before and after discretization is compared.

Following features are extracted from the music file:

- Centroid

- Flatness

- Entropy

- Tempo

- SwaraMean

- AvgPitch

The last attribute is the label which will hold the class of the Raag to which music file belongs. Label may be Bhairav, Yaman, Shanakara and Saarang. Figure 1

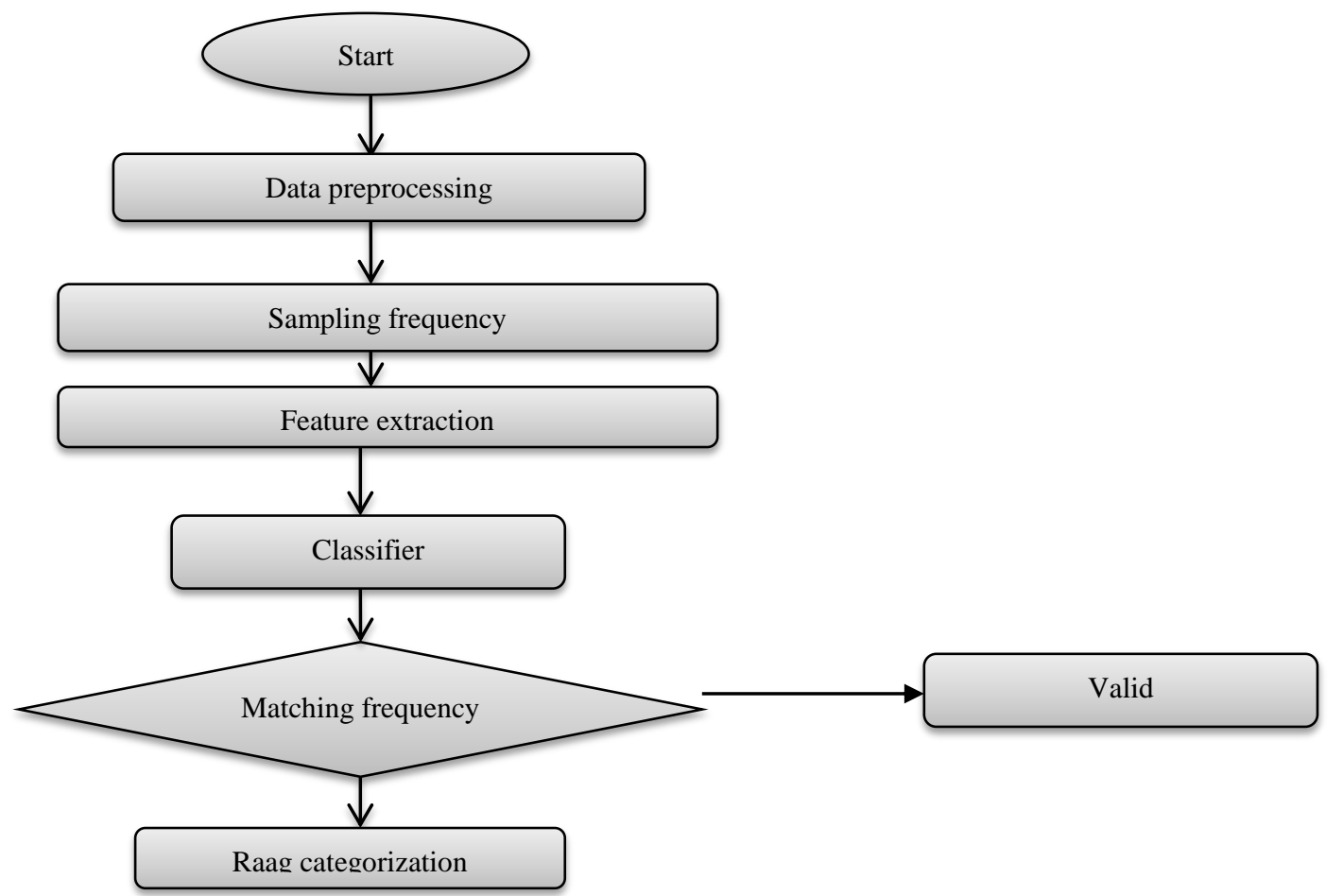

shows the generalized approach for the raag classification. Description of basic audio operations, data output and analytical operators mechanism along with the feature values in arff file format is shown in are applied supervised discretization on the dataset to increase the accuracy. Figure 2 shows the flowchart of the method presented.

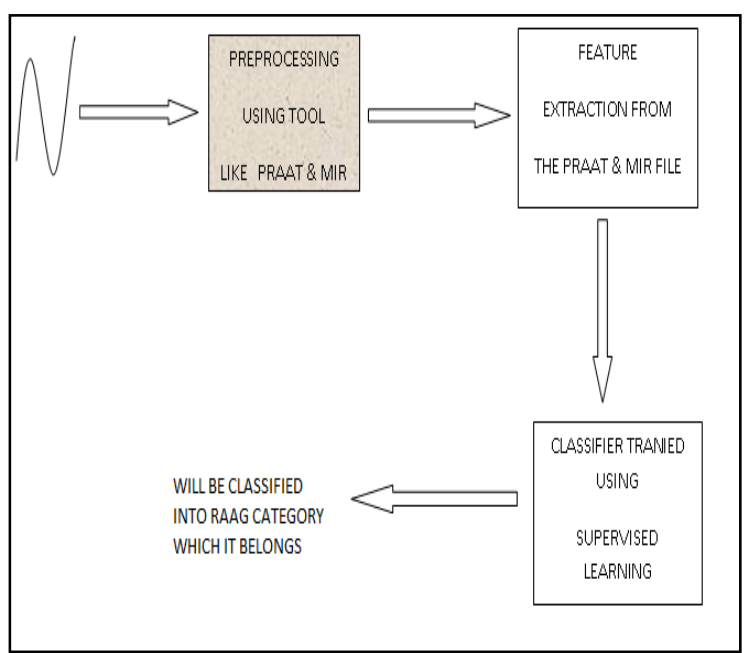

Figure 1Generalized approach for Raag classification

Figure 2 Flowchart 
Algorithms used in our proposed approach are to be discussed in the below sections:

- Multi-layer perceptron

- PART

Algorithm 1: Bayesian net

Step 1: A set of random variables to complete a cycle of a raag set.

Step 2: An arrangement of coordinated connections associates sets of hubs. The instinctive importance of a bolt from hub $\mathrm{X}$ to hub $\mathrm{Y}$ is that $\mathrm{X}$ affects $\mathrm{Y}$.

Step 3: Each node has a conditional probability table (CPT) that evaluates the impacts that the guardians have on the hub. The guardians of a hub $\mathrm{X}$ are every one of those hubs that have bolts indicating $X$.

Step 4: It shows the exponentially sized joint probability distribution (JPD) .

Each section in the JPD can be processed from the data in the $\mathrm{BN}$ by the chain $P(b \mid a)=\frac{P(a \mid b) * P(b)}{P(a)}$

Algorithm 2: Support vector machine (SVM)

Goal: 1) Correctly classify all training data

if $y_{i}=+1$

if $y_{i}=-1$

for all $\mathrm{i}$

2) Maximize the margin same as minimize

$$
\begin{aligned}
& M=\frac{2}{|w|} \\
& \frac{1}{2} w^{t} w
\end{aligned}
$$

3) We can formulate a Quadratic Optimization Problem and solve for $\mathrm{w}$ and $\mathrm{b}$

Minimize

$\Phi(w)=\frac{1}{2} w^{t} w$

subject to

$$
y_{i}\left(w x_{i}+b\right) \geq 1
$$

\section{Algorithm 3: Decision Tree}

/Takes an arrangement of characterized cases and /a rundown of properties, atts. Gives back the /root hub of a choice tree

Make hub N;

On the off chance that cases are all in same class

At that point RETURN N marked with that class;

On the off chance that atts is vacant

At that point RETURN N marked with modular case class;

best_att = choose_best_att(examples,atts);

mark $\mathrm{N}$ with best_att;

62
FOR every quality ai of best_att

si = subset case with best_att $=$ ai;

On the off chance that si is not vacant

At that point

new_atts = atts - best_att;

subtree = build_dec_tree(si,new_atts);

connect subtree as offspring of $\mathrm{N}$;

ELSE

Make leaf hub L;

Name L with modular illustration class; connect $\mathrm{L}$ as offspring of $\mathrm{N}$;

Return N;

\section{Algorithm 4: Random forest}

Step 1: Every tree is developed utilizing the accompanying calculation:

Step 2: Give the quantity of preparing cases a chance to be $\mathrm{N}$, and the quantity of variables in the classifier be $\mathrm{M}$.

We are told the number $m$ of information variables to be utilized to decide the choice at a hub of the tree; $\mathrm{m}$ ought to be a great deal not as much as M.

Pick a preparation set for this tree by picking $\mathrm{n}$ times with substitution from all $\mathrm{N}$ accessible preparing cases (i.e. take a bootstrap test). Utilize whatever is left of the cases to gauge the blunder of the tree, by foreseeing their classes.

For every hub of the tree, arbitrarily pick m variables on which to base the choice at that hub. Figure the best split in view of these $m$ variables in the preparation set. Every tree is completely developed and not pruned (as might be done in building a typical tree classifier).

For expectation another example is pushed down the tree. It is doled out the mark of the preparation test in the terminal hub it winds up in. This methodology is iterated over all trees in the group, and the normal vote of all trees is accounted for as irregular woods forecast.

\section{Algorithm 5: Multi-layer perceptron}

Step 1: Initialize weights randomly, pick a learning rate $\eta$

Until system is prepared:

For every preparation illustration i.e. info example and target output(s):

Step 2: Do forward go through net (with settled weights) to deliver output(s)

i.e., in Forward Direction, layer by layer:

Inputs connected

Increased by weights 
Summed "combined" by sigmoid enactment capacity Step 3: Yield went to every neuron in next layer Rehash above until system output(s) created.

Compute delta or neighborhood angle for each yield unit $\delta \mathrm{k}$

Layer-by-layer, register mistake (delta or nearby angle) for each concealed unit $\delta \mathrm{j}$ by backpropagating error (as indicated beforehand)

Step 4: Next, overhaul every one of the weights $\Delta$ wij By slope plummet, and do a reversal to Step 2

The general MLP learning calculation, including forward pass and backpropagation of blunder (until the system preparing finish), is known as the Generalized Delta Rule (GDR), or all the more usually, the Back Propagation (BP) calculation.

Step 5: This was a solitary cycle of back-propagation preparing requires numerous cycles with numerous preparation cases or ages (one age is whole presentation of complete preparing set). It can be moderate. Note that calculation in MLP is neighbourhood (as for every neuron).

Step 6: Parallel calculation usage is likewise conceivable.

\section{Results and analysis}

A tool which is used for both Data mining and Machine Learning is WEKA. It was first implemented by The University of Waikato, New Zealand, in 1997. It is a collection of an enormous number of Machine Learning and Data Mining algorithms. One drawback of this software is that it supports data files only written in ARFF (attribute relation file format) and CSV (comma separated values) format. Initially, it was written in $\mathrm{C}$ but later on it was rewritten in JAVA language. It comprises of a GUI interface for interaction with the data files. It possesses 49 data pre-processing tools, 15 attribute evaluators, 76 classification algorithms and 10 search algorithms for the purpose of feature selection. It comprises of three different types of graphical user interfaces (GUI's):- "The Explorer", "The Experimenter", and "The Knowledge Flow". WEKA provides the opportunity for the development of any new Machine Learning algorithm. It contains visualization tools and a set of panels to execute the desired tasks.
Weka has user friendly GUI and is used widely by majority of the users working in the field of machine learning. In this work of Raag detection in music other tools like MIRToolbox are also used to extract features from the music that's why instead of writing codes and using inbuilt libraries for machine learning Weka is used here. Classification algorithms or classifiers are used to basically sort out the network traffic into normal and anomaly categories. The objective behind classification techniques is to achieve high accuracy and precision and to classify the objects.

Classifiers can be broadly classified into eight types in WEKA, where various machine learning algorithms reside in each category.

A series of experiments have been conducted to compare different supervised learning techniques for Raag detection. Different existing techniques are considered for comparing the ability and efficiency of detecting the variants of Raag detection techniques with these existing techniques. Then precision and recall for all the classifiers are calculated. Precision and recall are interpreted concerning the retrieval and the set of relevancy in those retrieval items are relevance. Numerically these are defined as follows:

$$
\begin{aligned}
& \text { Precision }=\frac{\text { True positive }}{\text { True positive }+ \text { False positive }} \\
& \text { Recall }=\frac{\text { True positive }}{\text { True positive }+ \text { False negative }}
\end{aligned}
$$

The results of different classifiers for precision and recall have been shown in the below tables. The results are shown in Table 2-Table 11.

\section{(a) Bayesian Net}

Table 2 Precision and recall in case of Bayesian Net

\begin{tabular}{lllll}
\hline S.NO. & $\begin{array}{l}\text { True } \\
\text { positive }\end{array}$ & $\begin{array}{l}\text { False } \\
\text { positive }\end{array}$ & Precision & Recall \\
\hline Bhairav & 0.680 & 0.0040 & 0.850 & 0.680 \\
Yaman & 0.880 & 0.013 & 0.957 & 0.880 \\
Shankara & 0.720 & 0.147 & 0.621 & 0.720 \\
Saarang & 0.600 & 0.173 & 0.536 & 0.600 \\
Weighted & 0.720 & 0.093 & 0.741 & 0.720 \\
average & & & &
\end{tabular}


Ekta Patel et al.

\section{(b) Naive Bayes}

Table 3 Precision and recall in case of naive BAYES

\begin{tabular}{lllll}
\hline S.NO. & $\begin{array}{l}\text { True } \\
\text { positive }\end{array}$ & $\begin{array}{l}\text { False } \\
\text { positive }\end{array}$ & Precision & Recall \\
\hline Bhairav & 0.680 & 0.067 & 0.773 & 0.680 \\
Yaman & 1.000 & 0.027 & 0.926 & 1.000 \\
Shankara & 0.840 & 0.160 & 0.636 & 0.840 \\
Saarang & 0.480 & 0.080 & 0.667 & 0.480 \\
Weighted & 0.750 & 0.083 & 0.750 & 0.750 \\
average & & & & \\
& & & & \\
\hline
\end{tabular}

\section{(c) PART}

Table 4 Precision and recall in case of PART

\begin{tabular}{lllll}
\hline S.NO. & $\begin{array}{l}\text { True } \\
\text { positive }\end{array}$ & $\begin{array}{l}\text { False } \\
\text { positive }\end{array}$ & Precision & Recall \\
\hline Bhairav & 0.800 & 0.107 & 0.714 & 0.800 \\
Yaman & 0.880 & 0.053 & 0.846 & 0.880 \\
Shankara & 0.800 & 0.160 & 0.625 & 0.800 \\
Saarang & 0.240 & 0.107 & 0.429 & 0.240 \\
Weighted & 0.680 & 0.107 & 0.654 & 0.680 \\
average & & & & \\
\hline
\end{tabular}

(d) J48

Table 5 Precision and recall in case of J48

\begin{tabular}{lllll}
\hline S.NO. & $\begin{array}{l}\text { True } \\
\text { Positive }\end{array}$ & $\begin{array}{l}\text { False } \\
\text { Positive }\end{array}$ & Precision & Recall \\
\hline Bhairav & 0.800 & 0.120 & 0.690 & 0.800 \\
Yaman & 0.880 & 0.053 & 0.846 & 0.880 \\
Shankara & 0.760 & 0.147 & 0.633 & 0.760 \\
Saarang & 0.320 & 0.093 & 0.533 & 0.320 \\
Weighted & 0.690 & 0.103 & 0.676 & 0.690 \\
average & & & & \\
\hline
\end{tabular}

The results shown below clearly indicate that the accuracies of all the classifiers after the discretization have increases considerably. While the accuracy of the probability based classifier are best in this Raag detection from music.

The graph shown in Figure 3 suggested that the accuracy of all the classifiers used is compared before and after discretization. Data discretization is defined as a procedure of changing over constant information property estimations into a limited arrangement of interims and taking up with every interim some particular information esteem. Figure 4 presented the comparative graph based on the result obtained and the previous results.

(e) Random Forest
Table 6 Precision and recall in case of Random Forest

\begin{tabular}{lllll}
\hline S.NO. & $\begin{array}{l}\text { True } \\
\text { Positive }\end{array}$ & $\begin{array}{l}\text { False } \\
\text { Positive }\end{array}$ & Precision & Recall \\
\hline Bhairav & 0.600 & 0.067 & 0.750 & 0.600 \\
Yaman & 1.000 & 0.053 & 0.862 & 1.000 \\
Shankara & 0.840 & 0.120 & 0.700 & 0.840 \\
Saarang & 0.480 & 0.120 & 0.571 & 0.480 \\
Weighted & 0.730 & 0.090 & 0.721 & 0.730 \\
average & & & & \\
\hline
\end{tabular}

\section{(f) Multi-layer perceptron Results}

Table 7 Precision and recall in case of multilayer perceptron

\begin{tabular}{lllll}
\hline S.NO. & $\begin{array}{l}\text { True } \\
\text { Positive }\end{array}$ & $\begin{array}{l}\text { False } \\
\text { Positive }\end{array}$ & Precision & Recall \\
\hline Bhairav & 0.560 & 0.080 & 0.700 & 0.560 \\
Yaman & 0.840 & 0.053 & 0.840 & 0.840 \\
Shankara & 0.680 & 0.133 & 0.630 & 0.680 \\
Saarang & 0.440 & 0.227 & 0.393 & 0.440 \\
Weighted & 0.630 & 0.123 & 0.641 & 0.630 \\
average & & & & \\
& & & & \\
\hline
\end{tabular}

\section{(g) Decision Table}

Table 8 Precision and recall in case of decision table

\begin{tabular}{lllll}
\hline S.NO. & $\begin{array}{l}\text { True } \\
\text { Positive }\end{array}$ & $\begin{array}{l}\text { False } \\
\text { Positive }\end{array}$ & Precision & Recall \\
\hline Bhairav & 0.520 & 0.080 & 0.684 & 0.520 \\
Yaman & 1.000 & 0.040 & 0.893 & 1.000 \\
Shankara & 0.880 & 0.213 & 0.579 & 0.880 \\
Saarang & 0.240 & 0.120 & 0.400 & 0.240 \\
Weighted & 0.660 & 0.113 & 0.639 & 0.660 \\
average & & & & \\
\hline
\end{tabular}

\section{(h) Support vector machine}

Table 9 Precision and recall in case of SVM Results

\begin{tabular}{lllll}
\hline S.NO. & $\begin{array}{l}\text { True } \\
\text { positive }\end{array}$ & $\begin{array}{l}\text { False } \\
\text { positive }\end{array}$ & Precision & Recall \\
\hline Bhairav & 0.680 & 0.0040 & 0.850 & 0.680 \\
Yaman & 0.880 & 0.013 & 0.957 & 0.880 \\
Shankara & 0.720 & 0.147 & 0.621 & 0.720 \\
Saarang & 0.600 & 0.173 & 0.536 & 0.600 \\
Weighted & 0.720 & 0.093 & 0.741 & 0.720 \\
average & & & & \\
& & & & \\
\hline
\end{tabular}

Table 10 Accuracies of all classifiers before and after discretization

\begin{tabular}{lll}
\hline Classifier & $\begin{array}{l}\text { Accuracy (Before } \\
\text { Discretization) }\end{array}$ & $\begin{array}{l}\text { Accuracy (After } \\
\text { Discretization) }\end{array}$ \\
\hline Naïve Bayes & 75 & 80 \\
SVM & 75 & 78 \\
J48 & 69 & 75 \\
\hline
\end{tabular}




\begin{tabular}{lll}
\hline Classifier & $\begin{array}{l}\text { Accuracy } \\
\text { Discretization) }\end{array}$ & $\begin{array}{l}\text { (Before } \\
\text { Accuracy } \\
\text { Discretization) }\end{array}$ \\
\hline Random Forest & 73 & 74 \\
Decision Table & 66 & 73 \\
PART & 68 & 75 \\
Multi-layer & 63 & 75 \\
perceptron & & \\
\hline
\end{tabular}

\section{Comparison of accuracy for all classifiers}

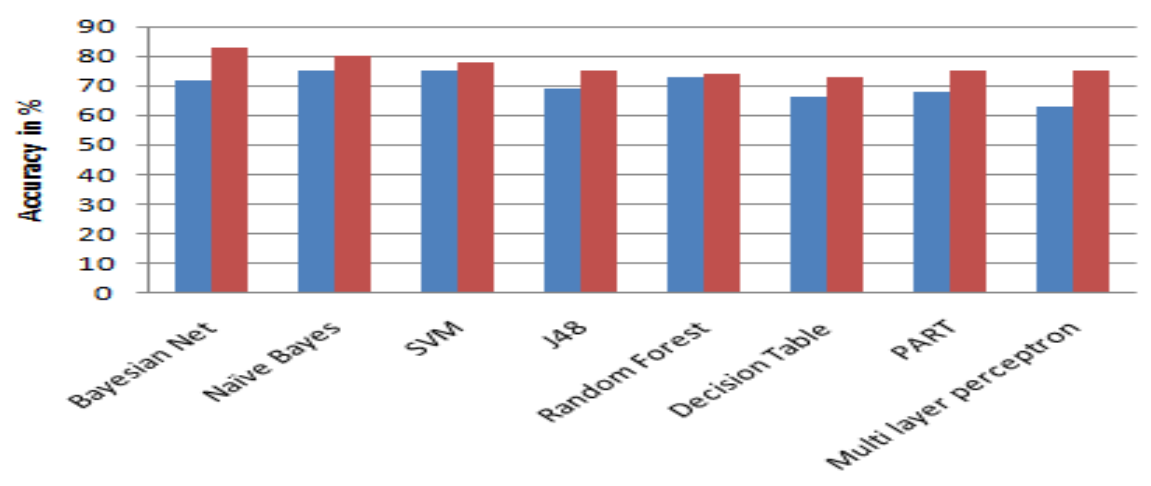

- Before Discretization

- After Discretization

Different Classifiers used for Raag Detection

Figure 3 Accuracies of all the classifiers

Table 11 Comparison with previous classification for Raag detection

\begin{tabular}{llllll}
\hline \multicolumn{1}{c}{ S. NO } & Classifier & $\begin{array}{l}\text { Accuracy } \\
\text { Discretization) }\end{array}$ & $\begin{array}{l}\text { (After } \\
\text { Accuracy } \\
{[\mathbf{2 2}]}\end{array}$ & $\begin{array}{l}\text { Accuracy } \\
{[\mathbf{2 3}]}\end{array}$ & $\begin{array}{l}\text { Accuracy } \\
{[\mathbf{2 4}]}\end{array}$ \\
\hline 1 & Bayesian Net & 83 & NA & NA & NA \\
2 & Naïve Bayes & 80 & 43.94 & NA & NA \\
3 & SVM & 78 & NA & 76.9 & 71.92 \\
4 & J48 & 75 & 50.5 & NA & NA \\
5 & Random Forest & 74 & NA & NA & NA \\
6 & Decision Table & 73 & NA & NA & NA \\
7 & PART & 75 & NA & NA & NA \\
8 & Multi-layer & 75 & & & NA \\
\hline
\end{tabular}

*NA: Not available

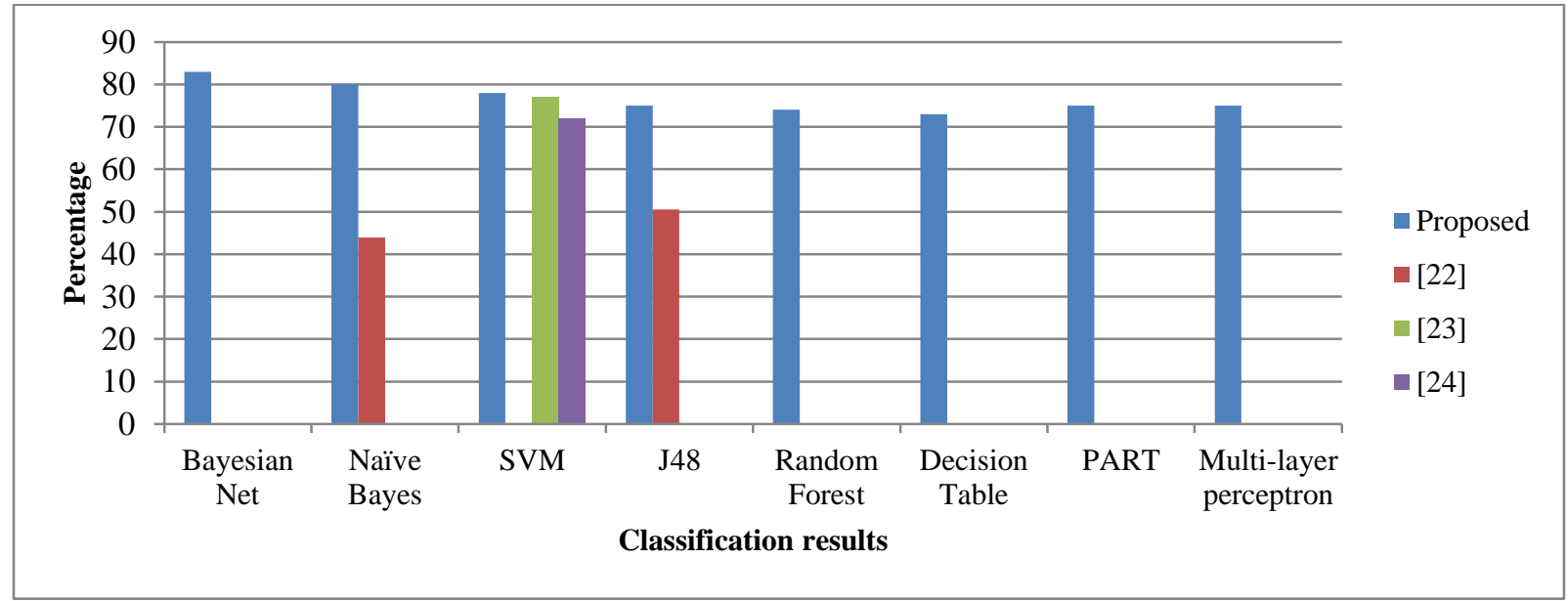

Figure 4 Comparison with previous classification algorithms 


\section{Discussion and conclusions}

There are several research work is in progress in the direction of Raag detection. It is the unique sequence in music which comprises of five to nine musical notes in melodic music. It depends on the pitch of musical notes and the mood in which they are conveyed rather than the sequence of notes. Its accurate detection is helpful in generating correct and accurate Raag with the different musical instrument. There are several obstacles in accurate Raag detection technique. The major challenges are the complex parameters like pitch and mood in the music, skipping extra tones, conversion of different data attributes and Raag tempo. In this paper a study and analysis have been presented to stumble the gaps and finding the advantages of the previous approaches. The previous research suggests supervised and unsupervised learning both for raag detection. So this paper included the methods from above two for comparison. This study shows that the supervised learning is capable in improving the detection results.

In this paper eight classifiers like Bayesian net, naive Bayes, SVM, J48, decision table, random forest, multi-layer perceptron and PART are considered for musical instrument Raag detection. The results are compared before and after discretization. The results indicate that the accuracies of all the classifiers after the discretization have increases considerably. While the accuracy of the probability based classifier are better in this Raag detection from music. Bayesian Net provides better results in all of them.

\section{Acknowledgment}

None.

\section{Conflicts of interest}

The authors have no conflicts of interest to declare.

\section{References}

[1] Bhatkhande V. Raga parichay. Hindusthani sangeet paddhati. Sangeet Karyalaya. 1934:50-212.

[2] Sharma AK, Panwar A, Chakrabarti P. Analytical Approach on Indian Classical Raga Measures by Feature Extraction with EM and Naive Bayes. International Journal of Computer Applications. 2014; 107(6):41-6.

[3] Chordia P, Şentürk S. Joint recognition of raag and tonic in north indian music. Computer Music Journal. 2013; 37(3):82-98.

[4] Tzanetakis G, Cook P. Musical genre classification of audio signals. IEEE Transactions on Speech and Audio Processing. 2002; 10(5):293-302.
[5] Vaska JS, Sowjanya AM. Clustering diabetics data Using M-CFICA. International Journal of Advanced Computer Research. 2015; 5(20):327-33.

[6] Govindarajan M. Sentiment analysis of movie reviews using hybrid method of naive Bayes and genetic algorithm. International Journal of Advanced Computer Research. 2013; 3(4):139-45.

[7] Chordia P, Rae A. Understanding emotion in raag: an empirical study of listener responses. Computer Music Modeling and Retrieval. Sense of Sounds. 2008:11024.

[8] Downie JS. Music information retrieval. Annual Review of Information Science and Technology. 2003; 37(1):295-340.

[9] Agrawal MN, Mahajan AM, Badgujar CD, Mande HP, Dixit G. Horizontal aggregation in SQL to prepare dataset for generation of decision tree using C4. 5 algorithm in WEKA. International Journal of Advanced Computer Research. 2013; 3(3):164-9.

[10] Bhuvaneswari C, Aruna P, Loganathan D. Classification of lung diseases by image processing techniques using computed tomography images. International Journal of Advanced Computer Research. 2014; 4(1):87-93.

[11] Fu Z, Lu G, Ting KM, Zhang D. Learning sparse kernel classifiers for multi-instance classification. IEEE Transactions on Neural Networks and Learning Systems. 2013; 24(9):1377-89.

[12] Dubey AK, Dubey AK, Agarwal V, Khandagre Y. Knowledge discovery with a subset-superset approach for mining heterogeneous data with dynamic support. In software engineering (CONSEG), 2012 CSI sixth international conference on 2012 (pp. 1-6). IEEE.

[13] Sinha AK, Singh V. Transformation of LOG file using LIPT technique. International Journal of Advanced Computer Research. 2016; 6(23):58-64.

[14] Lerner U, Moses B, Scott M, McIlraith S, Koller D. Monitoring a complex physical system using a hybrid dynamic Bayes net. In proceedings of the eighteenth conference on uncertainty in artificial intelligence 2002 (pp. 301-10). Morgan Kaufmann Publishers Inc.

[15] McCormick TH, Raftery AE, Madigan D, Burd RS. Dynamic logistic regression and dynamic model averaging for binary classification. Biometrics. 2012; 68(1):23-30.

[16] Zhao L, Ichise R. Instance-based ontological knowledge acquisition. In extended semantic web conference 2013 (pp. 155-69). Springer Berlin Heidelberg.

[17] Rajput A, Aharwal RP, Dubey M, Saxena SP, Raghuvanshi M. J48 and JRIP rules for e-governance data. International Journal of Computer Science and Security. 2011; 5(2):201.

[18] Patil TR, Sherekar SS. Performance analysis of Naive Bayes and $\mathrm{J} 48$ classification algorithm for data classification. International Journal of Computer Science and Applications. 2013;6(2):256-61.

[19] Kushwah J, Singh D. Classification of cancer gene selection using random forest and neural network 
based ensemble classifier. International Journal of Advanced Computer Research. 2013; 3(2):30-4.

[20] Ujlambkar A, Upadhye O, Deshpande A, Suryawanshi G. Mood based music categorization system for bollywood music. International Journal of Advanced Computer Research. 2014; 4(1):223-30.

[21] Ross JC, Rao P. Detection of raga-characteristic phrases from Hindustani classical music audio. In Serra X, Rao P, Murthy H, Bozkurt B, editors. Proceedings of the 2nd CompMusic Workshop; 2012; Istanbul, Turkey. Barcelona: Universitat Pompeu Fabra; 2012. pp. 133-8. Universitat Pompeu Fabra.

[22] Sharma AK, Panwar A, Chakrabarti P, Vishwakarma S. Categorization of ICMR Using feature extraction strategy and MIR with ensemble learning. Procedia Computer Science. 2015; 57:686-94.

[23] Nanni L, Costa YM, Lumini A, Kim MY, Baek SR. Combining visual and acoustic features for music genre classification. Expert Systems with Applications. 2016; 45:108-17.

[24] Khonglah BK, Prasanna SM. Speech/music classification using speech-specific features. Digital Signal Processing. 2016; 48:71-83.

[25] Chakraborty S, De D. Pattern classification of Indian classical ragas based on object oriented concepts. International Journal of Advanced Computer Engineering \& Architecture. 2012; 2:285-94.
[26] Roy S, Bhakta P, De D, Chakrabarty S. Modeling high performance music computing using Petri Nets. In control, instrumentation, energy and communication (CIEC), 2014 International conference on 2014 (pp. 678-82). IEEE.

[27] Gómez E, Herrera P. Estimating The Tonality Of Polyphonic Audio Files: Cognitive Versus Machine Learning Modelling Strategies. In ISMIR 2004.

[28] Priya K, Ramani RG, Jacob SG. Data mining techniques for automatic recognition of carnatic raga swaram notes. International Journal of Computer Applications. 2012; 52(10).

[29] Kumari P, Dandawate YH, Bidkar A. Raga analysis and classification of instrumental music. International conference on information engineering, management and security 2015 (pp. 294-401). ASDF.

[30] Chordia P, Rae A. Real-time raag recognition for interactive music. In NIME 2008 (pp. 331-334).

[31] Rao P, Ross JC, Ganguli KK, Pandit V, Ishwar V, Bellur A, Murthy HA. Classification of melodic motifs in raga music with time-series matching. Journal of New Music Research. 2014; 43(1):115-31.

[32] Sell G, Mysore GJ, Chon SH. Musical Instrument Detection. Center for Computer Research in Music and Acoustics. 2006. 